\title{
Nano fibres by electro spinning, properties and applications
}

\begin{abstract}
Electro spinning is a simple and versatile technique applicable to a wide range of polymers and solvents for the production of materials in nanometer scale. The nano fibrous materials produced by electro spinning process exhibit novel and significantly improved physical, chemical and biological properties. The small fibre diameter and the porous structure of the electrospun surfaces enable them for a wide range of applications such as wound dressing, tissue engineering scaffolds, vascular grafts, filters, membranes and sensors. In this article the principle, setup, materials used and the factors affecting the electro spinning process have been described. Also the properties \& applications of electrospun fibres and the limitations \& future scope of electro spinning process have been highlighted.
\end{abstract}

Keywords: electro spinning, nano fibre, mechanical properties, polymer solution, polymer melt
Volume 2 Issue 5 - 2017

\author{
R Nayak,' R Padhye \\ 'Fashion and Textiles Merchandising, School of Communication \\ and Design, RMIT University, Vietnam \\ ${ }^{2}$ School of Fashion \& Textiles, RMIT University, Australia
}

\begin{abstract}
Correspondence: R Nayak, Fashion and Textiles Merchandising, School of Communication and Design, RMIT University Vietnam, Saigon South Campus, 702 Nguyen Van Linh, District 7,Vietnam, Tel 84837761300, Fax 84837761399, Email rajkishore.nayak@rmit.edu.vn
\end{abstract}

Received: May 18, 2017 | Published: August 22, 2017
Abbreviations: DC, normally direct current; AC, alternating current; PEO, polyethylene oxide; PET, polyethylene terephthalate; PAN, polyacrylonitrile; PBS, oly butylenes succinate; PVA, polyvinyl alcohol; PS, polystyrene; PPFEMA, polyperfluoroalkyl ethyl methacrylate; PGA, oly glycolic acid, PEVA, polyethylene-co-vinyl acetate; CNTs, carbon nano tubes; SWNT, single wall nano tubes; PDLA, poly-dl-lactic acid; PLA, polylactic acid; TEBAC, tetraethyl benzyl ammonium chloride; DMF, N, n-dimethyl formamide; PVC, polyvinyl chloride; PLLA, poly-l-lactic acid; SEM, scanning electron microscopy; TEM, transmission electron microscopy; WAXD, wide angle $\mathrm{x}$-ray diffraction; SAXS, small angle x-ray scattering; DSC, differential scanning calorimetry; TGA, thermos-gravimetric analysis; NMR, nuclear magnetic resonance; FTIR, fourier transform infrared; WAXD, wide angle x-ray diffraction; PCL, polycaprolactone.

\section{Introduction}

Electro spinning or electrostatic spinning is the process of producing fibrous structures in nanometer range (diameter 40 to $2000 \mathrm{~nm}$ ) by subjecting a fluid jet to a high electric field. ${ }^{1}$ The conventional process of fibre spinning is based on the principle of pressure-driven extrusion of a viscous polymer into fibres of diameter ranging from 10 to $500 \mu \mathrm{m} .{ }^{2}$ The origin of electro spinning as a viable technique for producing nano fibres can be traced back to 1934 when Formhals patented his first invention relating to the process and the apparatus for producing artificial filaments using electric charges. ${ }^{3}$ Though the method had been experimented with for a long time, it had not gained importance until Formhals's invention due to some technical difficulties in earlier spinning methods, such as fibre drying and collection.

In the last few years the work of many researchers have made the electro spinning process suitable for processing of wide variety of biopolymers, engineering plastics, conducting polymers, block copolymers, ceramics and composite materials to produce nano fibres with controllable diameters. Due to the bending instability of the highly charged jet, the electrospun fibres are collected in the form of random oriented nonwoven mat. Although these mats are suitable to be used in many areas such as composite reinforcement, membrane based separation, enzyme immobilization, sensing and tissue engineering, are not suitable for the structure where alignment is the prime requirement. Many attempts have also been made to align the fibres in specific patterns, to stack layer-by-layer to produce composites. The aligned nano fibres can be potentially applied in composite materials, reinforcements, electrochemical sensing, bone and blood vessel engineering and tissue engineering. ${ }^{4-6}$ The electrospun nano fibres have very large surface area to volume ratio and porous structure as compared to the conventional fibre. Due to this reason these fibres can be used in adsorption of chemicals, military and civilian filtration. ${ }^{7}$

A wide range of fabric properties such as strength, thickness, weight, porosity, surface functionality can be achieved depending on the specific polymer being used. This novel technique of electro spinning provides the capacity to lace together a variety of types of polymers, fibres, and particles to produce ultra thin layers. Small insoluble particles can be added to the polymer solution and encapsulated in the dry nano fibres. Soluble drugs or bacterial agents can be added and electrospun into nonwoven mats.

\section{Electro spinning process}

Electro spinning or electrostatic spinning is a simple and unique process to produce fine fibres by electrostatic forces. It is based on the basic principle of effect of electrostatic force on liquids i.e. when a suitably electrically charged material is brought near to a droplet of liquid held in a fine capillary, it would form a cone shape and small droplets would be ejected from the tip of the cone if the charge density is very high. Though the principle of electro spinning can be date back to $1800 \mathrm{~s},{ }^{8}$ the first noticeable work done was by Formhals. It combines the principles of both electro spaying and conventional wet spinning of fibres. Some other techniques which work similarly to electro spinning are electrostatic precipitators and pesticide sprayers. The following section will focus on the electro spinning setup and working. 


\section{The setup}

The basic setup used for electro spinning is very simple in construction which is shown in Figure 1. It consists of three major components namely, high voltage power supply, Syringe and Collector. Though many researchers use the setup as shown in the figure, some researchers modify to generate a wide variety of fine fibres.

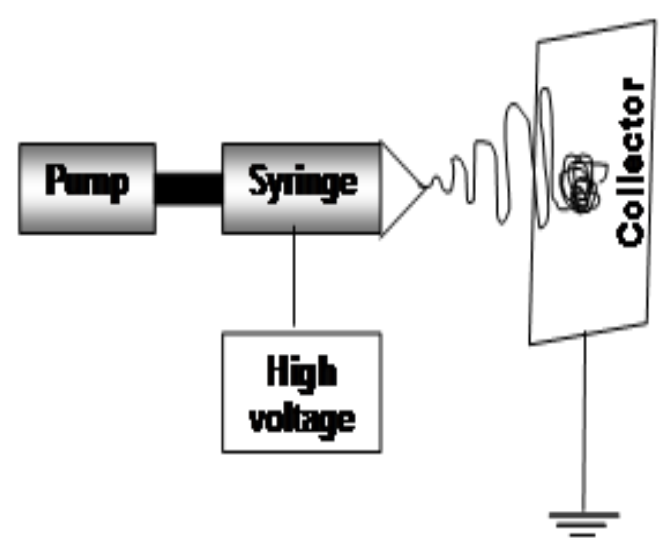

Figure I The Setup for Electro spinning.

High voltage power supply: Normally Direct Current (DC) is used as the source of power supply though there is feasibility of using Alternating Current (AC). Very high voltage (usually in the range of $1-30 \mathrm{kV}$ ) is required for electro spinning. The polarity of the electro spinning system is arbitrary and can be reversed depending upon the polymer type and final product. The free charges are induced to the polymer solution through an immersed electrode. The charged ions of the polymer solution move in response to the external applied electric field towards the collector of opposite polarity.

Syringe: The syringe or pipette is a very fine capillary tube. It holds the polymer solution or melt into which a metal electrode is inserted. It is mounted horizontally or vertically on an adjustable electrically insulating stand. The spinneret is connected to the syringe at one end. During the spinning process the syringe pump is used to supply polymer at a constant and controllable rate.

Collector: The collector or the collecting surface is used to collect the electrospun fibres. Surfaces of different geometry and configurations are used to alter the alignment of the nano fibres. The collector is mounted on an insulating stand so that its potential can be controlled.

Working: The polymer solution held in the syringe is electrified by the application of a very high voltage and the charges are evenly distributed on the surface. When an electric field is applied to the end of the capillary tube, a charge is induced on the surface of the liquid. Now the polymer drop which is held by its surface tension at the tip of the spinneret, experiences an electrostatic repulsion force between the surface charges and the columbic force exerted by the external electric field. As the electric field intensity is increased, the repulsion force is increased which distorts the hemispherical liquid drop into a conical object commonly known as Taylor cone (Figure 2).

When the electric field reaches a threshold value at which the repulsive electrical forces overcome the surface tension, a charged jet of the solution is ejected from the tip of the Taylor cone. As the charged liquid jet is accelerated in the air it undergoes a chaotic motion or bending instability that causes bending and allows the electrical forces to elongate the jet. ${ }^{9}$ Also the solvent is evaporated and its diameter is greatly reduced from hundreds of micrometers to tens of nanometers. ${ }^{10}$ As the jet becomes thinner in the electric field, radial charge repulsion results in splitting of the primary jet into multiple filaments, in a process known as splaying. The final fibre diameter is determined primarily by the number of subsidiary jets formed. The charged jet is attracted by the grounded collector plate and is collected randomly on its surface.

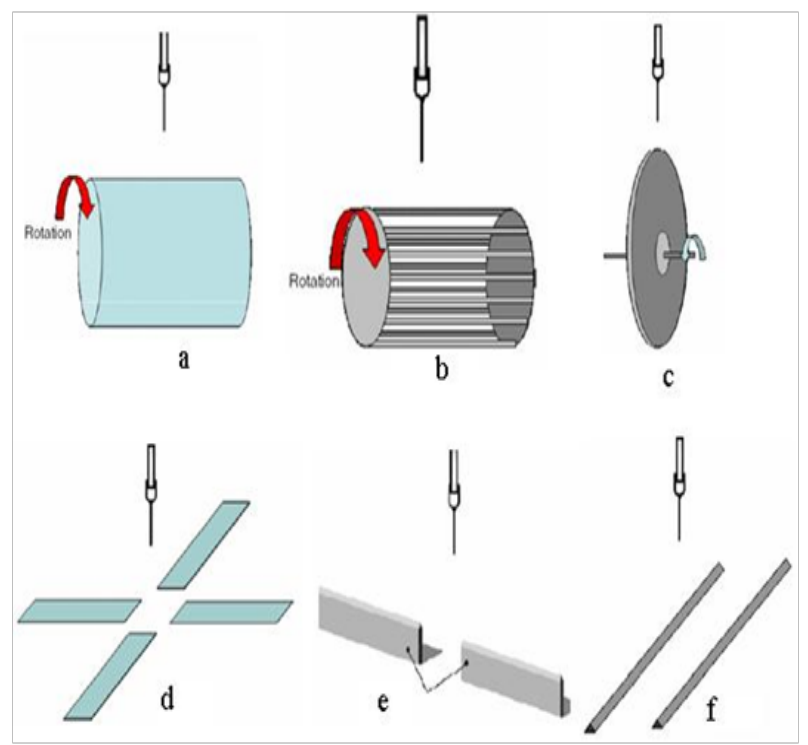

Figure 2 Various types of collectors (a, rotating drum, b, rotating wire drum, c, disc, d, array of counter electrodes, e, counter electrodes, f, parallel electrodes).

\section{Materials used for electro spinning}

All the early works on electro spinning was mainly on conventional organic polymers with high molecular weight which could be dissolved in suitable solvents. Subsequently many researchers worked on it and diversified the materials that can be used for electro spinning. Until recently, about 50 polymers have been successfully electrospun. An advantage of electro spinning is that polymers both in solution and melt can be used. ${ }^{11}$ Electro spinning can be applied to a wide range of polymers such as polyolefine, polyamides, polyester, aramid, acrylic as well as biopolymers like proteins, DNA, polypeptides or other materials like photonic polymers. Electro spinning can also be extended to various functional materials (such as electrical, magnetic, ferroelectric and ferromagnetic) where an anisotropic alignment of active components is expected to bring in new features and applications. ${ }^{12}$ This section will highlight about various materials which can be successfully used in electro spinning.

Functional polymers and blends: Many synthetic and biopolymers can be used in the electro spinning process. Table 1 gives a list of the polymers and their solvents which are used in electro spinning. Larrondo \& Manley ${ }^{13}$ in an earlier work electrospun bulk polyethylene and polyethylene dissolved in paraffin. Polyethylene oxide (PEO) has been electrospun by various researchers. ${ }^{14-16}$ The electro spinning of polyethylene terephthalate (PET), polyethylene naphthalate and their blends in the molten state was carried out by Kim \& Lee. ${ }^{17}$ Renker and co-workers electrospun polybenzimidazole, ${ }^{18}$ styrene-butadienestyrene triblock copolymer ${ }^{19}$ and carbon nano fibres. ${ }^{20}$ The electro 
spinning of poly-L-lactide, polycarbonate, polyvinylcarbazole ${ }^{21}$ and polyvinylpyrolidone ${ }^{22}$ were carried out by Bognitzki and co-workers. The electro spinning of nylon6, cellulose acetate, ${ }^{23}$ polyacrylonitrile (PAN) ${ }_{2}{ }^{24}$ polyurethane ${ }^{25}$ polycarbonate, ${ }^{26}$ polybutylenes succinate $(\mathrm{PBS})^{27}$ and polyvinyl alcohol (PVA) ${ }^{28}$ has also carried out. Baumgarten had earlier electrospun acrylic resins dissolved in dimethylformamide.

Table I List of materials and their solutions used for electro spinning

\begin{tabular}{|c|c|}
\hline Name of polymer & Solvent \\
\hline $\begin{array}{l}\text { Polyethylene terephthalate } \\
\text { (PET) }\end{array}$ & $\begin{array}{l}\text { Trifluoroacetic acid and } \\
\text { dichloromethane mixture }\end{array}$ \\
\hline Nylon & Formic acid \\
\hline Polyacrylonitrile (PAN) & Dimethylformamide (DMF) \\
\hline Cellulose acetate & Acetone \\
\hline Polyethylene Oxide (PEO) & Water or Chloroform \\
\hline Polybenzimidazole (PBI) & N, N-Dimethyl Acetamide \\
\hline Polyaniline & Sulphuric acid \\
\hline Polycarbonate & $\begin{array}{l}\text { DMF \& Tetrahydrofuran } \\
\text { (THF), }\end{array}$ \\
\hline Polyurethane & Dichloromethane, DMF \\
\hline Polyvinyl alcohol & Water \\
\hline Polystyrene & Tetrahydrofuran (THF) \\
\hline Poly-L-lactide (PLLA) & Dichloromethane \\
\hline Nylon 6-polyimide & Formic acid \\
\hline Polyhydroxybutyratevalerate & Chloroform \\
\hline Polybutylenes succinate & Chloroform \\
\hline DNA & Water \\
\hline Chitosan & Acetic acid \\
\hline Silk Fibroin & Formic acid \\
\hline $\begin{array}{l}\text { Polyvinylidiene difluoride- } \\
\text { trifluoroethylene (PVdF- } \\
\text { TrFE) }\end{array}$ & DMF \\
\hline
\end{tabular}

Table Continued...

\begin{tabular}{|c|c|}
\hline Name of polymer & Solvent \\
\hline Polyvinyl chloride & THF, DMF \\
\hline Polyaramid & Sulphuric acid \\
\hline Poly gamma benyzylglumate & Dimethylformamide (DMF) \\
\hline $\begin{array}{l}\text { Polyphenylene } \\
\text { terephthalamide }\end{array}$ & Sulphuric acid \\
\hline Polycaprolactone & Acetone \\
\hline $\begin{array}{l}\text { Styrene-Butadiene-Styrene } \\
\text { (SBS) triblock copolymer }\end{array}$ & 75\% THF\& 25\% DMF \\
\hline $\begin{array}{l}\text { Polyethylene-co-vinyl } \\
\text { acetate (PEVA) }\end{array}$ & Chloroform \\
\hline Polylactic acid & Chloroform \\
\hline $\begin{array}{l}\text { Poly(p-phenylene } \\
\text { terephthalamide) (PPTA) }\end{array}$ & 95-98 wt\% Sulphuric acid \\
\hline Polyamides & Phenol \\
\hline Polyamic acid & m-cresol \\
\hline Polyetherimide & Methylene chloride \\
\hline $\begin{array}{l}\text { Collagen (Type I calf skin } \\
\text { and Type III human placenta) } \\
\text { and elastin }\end{array}$ & $\begin{array}{l}\text { I,I,I,3,3,3-hexafluoro-2- } \\
\text { propanoln (HFP) }\end{array}$ \\
\hline
\end{tabular}

Koombhongse et al. ${ }^{29}$ has studied various shapes produced by electro spinning of different polymers such as Poly (2-hydroxyethyl methacrylate-HEMA), polystyrene (PS), Poly (vinylidene fluoride-PVDF) and Poly (ether imide). Sun et al. ${ }^{30}$ Produced compound core-shell polymer nano fibres by co-electro spinning. They generated two different structures with PEO-PEO as core \& sheath and PDT (polydodecylthiophene)-PEO core and sheath respectively and studied their properties. Pinto et al. ${ }^{31}$ Electro spun blends of polyaniline a conducting polymer with PEO in chloroform to produce filaments in the range of 4-20nm. The blend of Nylon 6 and Nylon 66 in formic acid with a solution of polyethylene terephthalate (PET) in triflouroaceticacid was electrospun to achieve a combination of properties of the components in the blend. ${ }^{32}$ High modulus electrospun fibres from kevlar and polyethylene terephthalate were obtained by Zacharides \& Porter. $^{33}$

Gupta \& Wilkes ${ }^{34}$ used two polymer solutions in a side-by-side fashion for two bicomponent systems-polyvinyl chloride/segmented polyurethane (PVC/Estane) and polyvinyl chloride/polyvinylidiene fluoride (PVC/PVDF). Ma et al. ${ }^{35}$ Used electro spinning and chemical vapour deposition to produce super hydrophobic fabrics by using electrospun PCL mats and polyperfluoroalkyl ethyl methacrylate (PPFEMA) coating. Poly [2-methoxy-5-(2-ethylhexyloxy)-1,4-phenylenevinylene] (MEH-PPV) was used in electro spinning in Table 1. ${ }^{36,37}$ 
Biological polymers: Calf thymus Na-DNA was electrospun by Fang et al. ${ }^{38}$ Electro spinning has been utilized to produce nano fibrous material from silk fibroin for biomedical applications because it has several distinctive biological properties including biocompatibility, good oxygen and water vapour permeability, biodegradability and minimal inflammatory reaction. ${ }^{39-41}$ Min et al. ${ }^{42}$ electro spun silk fibroin using formic acid as a solvent and studied its effect on adhesion and spreading of normal human keratinocytes and fibroblasts. Jin et al. ${ }^{43}$ used various compositions of silk/ polyethylene oxide (PEO) aqueous blends in electro spinning and investigated the potential as biomaterial scaffold. Electro spinning and the applicability of acid soluble, lyophilized collagen have been reported by Matthews and coworkers. ${ }^{44}$ Lou et al. ${ }^{45}$ used the electro spinning process to produce $\mathrm{PEO} /$ chitosan nano fibre membrane and evaluated their biocompatibility. Geng et al. ${ }^{46}$ Produced chitosan nano fibres by electro spinning of aqueous chitosan solution using concentrated acetic acid as a solvent. Kataphinan et al. ${ }^{47}$ produced a skin mask by directly electro spinning fibres onto the skin surface in order to protect or heal eventual wounds. The potential of electrospun collagen (Type I calf skin and Type III human placenta) and elastin in tissue engineering were investigated. ${ }^{48}$

Ceramics and metals: Li \& $\mathrm{Xia}^{49}$ fabricated Titania nano fibres with controllable diameters and porous structures by electro spinning of ethanol solution containing poly (vinyl pyrrolidone) PVP and titanium tetraisopropoxide. In an earlier work titanium tetraisopropoxide was mixed with PVP in 2-propanol from which TiO2/PVP composite films and optical wave guiding structures were fabricated. ${ }^{50}$ Kataphinan et al. ${ }^{51}$ Used organic and inorganic fibres based on glass/ceramic fibres for high temperature applications. Randomly oriented or uniaxially aligned arrays of magnetic nickel ferrite $\left(\mathrm{NiFe}_{2} \mathrm{O}_{4}\right)$ nano fibres with an average diameter of $46 \mathrm{~nm}$ were fabricated by electro spinning. ${ }^{52}$ The solution containing polyvinyl Pyrrolidone and alkoxide precursors to nickel and iron oxides was used followed by hydrolysis and calcination at $550^{\circ} \mathrm{C}$ in air.

Uniaxially aligned nano fibres of various materials such as $\mathrm{TiO}_{2}$, $\mathrm{TiO}_{2} / \mathrm{PVP}, \mathrm{Sb}$-doped $\mathrm{SnO}_{2}, \mathrm{Al}_{2} \mathrm{O}_{3}, \mathrm{Fe}_{2} \mathrm{O}_{3}, \mathrm{ZrO}_{2}, \mathrm{BaTiO}_{3}$ and $\mathrm{NiFe}_{2} \mathrm{O}_{4}$ have also been produced13,3. Thin fibres of alumina-borate oxide were prepared using sol-gel processing and an electro spinning technique which after calcination turned into ultra-fine fibres with a diameter of about $550 \mathrm{~nm} .^{53}$ The electro spinning process is used to fabricate scaffold from biomaterials such as PLA, polyglycolic acid (PGA), polyethylene-co-vinyl acetate (PEVA) and Type I collagen Bowling et al. ${ }^{54}$

Nano components: Carbon nano tubes (CNTs) possess special mechanical and electronic features e.g. a single carbon nano tube has a modulus of several thousands of GPa and a tensile strength of several tens of GPa. ${ }^{55}$ As carbon nano tubes are difficult to be aligned when they are used as reinforcement in composite fabrication, several researchers have tried to incorporate CNTs into nano fibres produced by electrospinning4-6. Ko et al. ${ }^{56}$ Dispersed single wall nano tubes (SWNT) to polyacrylonitrile solution to produce nano composite fibrils and characterized the structure, composition and physical properties of the nano composite fibrils. Park et al. ${ }^{57}$ dispersed the SWNT of $1.2-1.6 \mathrm{~nm}$ in diameter and $3 \mathrm{~mm}$ long in a polyimide (CP2) solution for electro spinning. Laxminarayana \& Jalili ${ }^{58}$ prepared nano composite fabrics made from carbon nano tubes (CNTs) in order to develop CNT-based piezoelectric strain sensors.

\section{Factors affecting electro spinning process}

The structure and morphology of the electrospun nanofibres is influenced by many factors related to the solution, the setup and the ambient conditions which are discussed in this section.

\section{Parameters related to solution}

Solution viscosity: Solution viscosity is one of the most important parameters affecting the diameter and morphology of the electrospun fibres. Below a threshold value the jet breaks and defects such as beads and droplets have been observed ${ }^{59-61}$ Electro spinning of polymers such as polyethylene oxide (PEO), polyacrylonitrile (PAN) $)^{62}$ and poly-DL-lactic acid (PDLA) ${ }^{63}$ is difficult below certain concentration levels. Geng et al. ${ }^{44}$ observed the formation of uniform chitosan fibres containing fewer defects with the increase in the solution viscosity. There were drastic morphological changes when chitosan concentration increased at the same molecular weight. The spraying of large beads in very thin fibres was obtained at $6 \%$ concentration because of insufficient chain entanglements. At $8 \%$ concentration fine fibres with some spindle like beads were formed in comparison to bead-free fibres at $7 \%$ concentration. It was thus established that at a molecular weight of $106,000 \mathrm{~g} / \mathrm{mol}, 7 \%$ chitosan concentration was the most suitable for uniform and bead-free fibre formation. An increase in diameter from $52 \mathrm{~nm}$ to $374 \mathrm{~nm}$ was observed by Li \& Xia ${ }^{64}$ during the electro spinning of $\mathrm{TiO}_{2} / \mathrm{PVP}$ composite fibers by varying the concentration of PVP from $0.02-0.06 \mathrm{~g} / \mathrm{ml}$.

Demir et al. ${ }^{31}$ used polyurethane in electro spinning and observed that the fibre diameter increase as the third power of solution concentration. It was also observed that at very high viscosities it is difficult to form the fibre due to drying of the solution at the tip of the spinneret and curly fibres are formed. It is reported that increasing ethanol concentration makes the solution viscosity higher and the surface tension lower which effects the formation of smooth filaments 60. It was observed that at a solution concentration of $3 \mathrm{mg} \mathrm{mL}^{-1}$ the width of MEH-PPV ribbons was around $200 \mathrm{~nm}$ and the width increased to $350 \mathrm{~nm}$ when the concentration changed to $5 \mathrm{mg} \mathrm{mL}^{-1}$. Also when the concentration reduced to $1 \mathrm{mg} \mathrm{mL}^{-1}$ the fibres became round in cross section with a mean diameter of $50 \mathrm{~nm}$.

Wu et al. ${ }^{24}$ studied the effect of solution concentration (PBS/CF) on electro spinning and found that when the concentration is less than $8 \%(\mathrm{w} / \mathrm{w})$, it is too dilute for electro spinning and only beads are formed. With a concentration of $8-12 \%(\mathrm{w} / \mathrm{w})$ discontinuous fibres with beads formed. When the concentration reaches $12 \%$ continuous porous fibres formed and at a concentration of $13 \%$, the average porous diameter is approximately $200 \mathrm{~nm}$. With further increase, the porous nano fibre morphology becomes obvious and the diameter of nanoholes is more uniform. When the concentration is $14 \%$ the average porous diameter is approximately $300 \mathrm{~nm}$. When the concentration exceeds $15 \%$, PBS solution becomes gelatinous due to quick solvent evaporation and the needle is blocked.

Solution surface tension: Surface tension is an influencing factor in the formation of beads. The surface tension depends upon the type of polymer-solvent combination and the solution viscosity. The surface tension coefficient depends on the polymer and solvent40. It has been reported that reduced surface tension favours the formation of fibres without beads. Bognitzki et al. ${ }^{39}$ obtained fibres with an average diameter of approximately $1 \mu \mathrm{m}$ during the electro spinning of biopolymer polylactic acid (PLA). They used tetraethyl benzyl ammonium chloride (TEBAC) to obtain fibres with lower diameter. The diameter was decreased by using TEBAC because of the increased surface tension and electrical conductivity that TEBAC procures. Also the same effect was observed by Adding PEO to the blend of PLA and polyvinilpyrrolidone because of an increase of surface tension. 
Theron et al. ${ }^{65}$ measured the surface tension of the polymer solution with a pulsating bubble surfacto meter. They compared the surface tension of solutions of PEO in ethanol/water (40/60) to that of a pure blend of ethanol/water (40/60) and suggested that the surface tension is mainly a function of the solvent in the solutions and tends to be less sensitive to variation in the polymer concentration. Ding et al. ${ }^{20}$ measured that high solution concentration gives high solution viscosity and surface tension. The split ability of the jet was decreased with the increase in the surface tension. It was earlier established that while there is a linear correlation between the surface tension of polymer and the critical voltage of process initiation, throughput is dependent on electric conductivity.

Solution conductivity: As almost all the polymers are mostly conductive (except few dielectrics), the net charge density of the solution is mainly affected by the applied electrostatic field and to a lesser extent by the conductivity of the solution. The addition of $\mathrm{NaCl}$ to a polyethylene oxide (PEO)/water solution is observed to increase the net charge density carried by the spinning jet which favours in the formation of uniform fibres with fewer beads. Also the diameter of the filaments increases with the decrease in net charge density, which makes the charge repulsion force smaller. Baumgarden 11 has investigated that the jet radius varied inversely to the cube root of the electrical conductivity of the solution. Zong et al.$^{66}$ Investigated that addition of ionic salts such as $\mathrm{KH}_{2} \mathrm{PO}_{4}, \mathrm{NaH}_{2} \mathrm{PO}_{4}$ and $\mathrm{NaCl}$ during electro spinning of PDLA produces beadless fibre with relative smaller diameter ranging from 200 to $1000 \mathrm{~nm}$. Demir et al. ${ }^{43}$ added triethyl benzyl ammonium chloride to increase the conductivity and observed the substantial increase in mass flow with the addition of small amount of salt. The PEO-water solution exhibits higher conductivity as compared to glycerol which leads to the formation of stable jets at lower field strengths. ${ }^{67}$

Molecular weight of polymer: The rheological and electrical properties such as viscosity, surface tension, conductivity and dielectric strength are affected by the molecular weight. The formation of beads with too low molecular weight polymers and fibres with larger average diameter with high molecular weight polymers has also been investigated ${ }^{68}$ Geng et al. ${ }^{59}$ has investigated that the electrospun fibres from lower molecular weight chitosan solution (9.5-10.5\%) were fragile and usually contained large size beads, while those from higher molecular weight chitosan solution (2.5-3\%) were rougher, finer and with some bead defects. Only fragile fibres with several droplets were produced with a molecular weight of $30,000 \mathrm{~g} /$ mol, uniform fibres were produced at molecular weight of 106,000 $\mathrm{g} / \mathrm{mol}$ and very fine fibres (average diameter 60nm) with rougher surfaces were produced at molecular weight of $398,000 \mathrm{~g} / \mathrm{mol}$. Gupta et al. ${ }^{69}$ Used polymethyl methacrylate (PMMA) in electro spinning and observed that as the molecular weight increased, the number of beads and droplets reduced. Also uniform fibres were obtained at a lower concentration and with a narrow molecular weight distribution.

Volatility of solvent: Volatility of the solvent is also an important factor which influences the phase separation process inside the chamber. The nano fibre diameter depends upon the solvent evaporation rate which in turn is affected by solvent vapour pressure. It has been reported that the average fibre diameter decreases with the increase in the amount of N, N-dimethyl formamide (DMF) in the tetrahydrofuran (THF)/DMF mixed solvent during the electro spinning of polyvinyl chloride (PVC) ${ }^{70}$ The electro spinning of poly-L-lactic acid (PLLA) with highly volatile solvent such as dichloromethane produced nano fibres with pore sizes of $100 \mathrm{~nm}$ in width and $250 \mathrm{~nm}$ in length along the fibre axis. ${ }^{71}$

\section{Parameters related to setup}

Syringe \& spinneret design: It has been investigated that for the production of a core-shell structure a dual chamber syringe is used. Many researchers have used multiple spinnerets in order to increase the productivity Ref. Multiple needle tips were used by Ding et al. ${ }^{72}$ to electrospun blend of PVA and cellulose acetate. They produced nano fibres with various weight ratios of PVA and cellulose acetate by using four tips and varying the number containing PVA and cellulose acetate. Li and Xia produced hollow nano fibres of two immiscible liquids by using a coaxial two capillary spinneret. This spinneret was also used by them to electrospun blends of polymers. ${ }^{73}$

Applied voltage/electric field strength: The external electric field is the fundamental requirement for electro spinning and an important factor governing the morphology and diameter of the electrospun fibers. With the increase in the electric field strength, the shape of the polymer tip changes from hemispherical shape to a spherical shape and then to a conical shape. At a certain field strength fine continuous jet is ejected beyond that the jet becomes unstable and multiple jets are ejected. Shin et al..$^{50}$ observed that with the increase in electric field, the polymer jet thins more rapidly and the cone region becomes shorter and more concave in profile. It has been observed that as electric field strength increases, the diameter of nano fibres decreases. Deitzel et al. ${ }^{34}$ showed that an increase in applied voltage changes the shape of the jet initiating point and the structure and morphology of fibres. Studied the effect of polarity on the electro spinning process. They found that inversing the polarity (when the collector is charged $\&$ needle grounded) lowers the production rate and results in coarser and less homogenous surfaces.

Kessick et al. ${ }^{75}$ performed the electro spinning by using both the $\mathrm{AC}$ and DC potential and found that the AC potential can reduce the amount of fibre whipping associated with DC potential. Thick fibres with spindle like beads were formed at an electric field of $1 \mathrm{kV} / \mathrm{cm}$. Uniform and homogeneous fibres were formed by increasing the electric field to a range of $3-4.5 \mathrm{kV} / \mathrm{cm}$ or more and above $4.5 \mathrm{kV} /$ $\mathrm{cm}$, much thinner fibres with many beads were formed because of increased elongation force and instability of charged jet induced by the stronger electric field.

At an electric field of lower than $0.6 \mathrm{kV} / \mathrm{cm}$, no stable liquid jets were obtained; increasing the electric field gradually resulted in formation of thinner nano fibers; at $1.6 \mathrm{kV} / \mathrm{cm}$ anatase nano fibers as thin as $30 \mathrm{~nm}$ were generated and when it was greater than $1.6 \mathrm{kV} / \mathrm{cm}$, the spinning jets became unstable and the average diameter was found to increase slightly with increasing field.

Polymer flow rate: The polymer flow rate of the PVP solution also influenced the diameter of the nano fibers. It is observed that at very high flow rate more beads are formed as the jet does not get enough time for drying. Also at higher flow rate the deposition pattern of the fibres become more random instead of regular and their diameter increases. This is because the jet is attracted with less charge density towards the collector. ${ }^{76}$ At lower flow rates the jet gets sufficient time for drying and its diameter decreases but the fibre formation is inconsistent. Megelski et al. ${ }^{77}$ Observed that the diameter of PS fibre and the pore size increased with an increase in the polymer flow rate. It was observed that reducing the flow rate of MEH-PPV solution, 
smaller fibres can be formed. It was shown that higher feeding rates often resulted in thicker fibers and the jets became unstable if the feeding rate exceeded $0.5 \mathrm{~mL} / \mathrm{h}$.

Collector distance and geometry: It has been observed that the jet diameter is decreased with the increase in the distance of the collector plate. There is a decrease of the jet diameter by a factor of 5 at a distance of $10 \mathrm{~mm}$ from the tip of the cone, indicating a large amount of stretching. Beyond a certain distance the jet becomes extreme thin and unsteady leading to the formation of beads. Though Collagen fibrils could be spun over very short distance of the collector, they contained considerable amount of solvent and were wet. Lou et al. ${ }^{36}$ observed that when the tip to collector distance is less than $10 \mathrm{~cm}$, the same electrical field can't spin the fibres because the solvent is not completely evaporated. Theron et al. ${ }^{61}$ used a sharp needle to position and align individual polymer nano fibres into parallel arrays. Sundary et al. ${ }^{78}$ aligned the as-spun nano fibres in parallel and cross patterns by using an insulated cylinder substrate (speed $2000 \mathrm{rpm}$ ) attached to the axle of a DC motor. Katta et al. ${ }^{79}$ Produced aligned nano fibre sheets of nylon- 6 by using a rotating copper wire drum as the collector.

The nano fibres were aligned more or less parallel to each other with a high speed rotating drum by Doshi \& Reneker. ${ }^{16}$ The use of a wheel-like bobbin as the collector to position and align individual polymer nano fibres into parallel arrays has also been reported. This technique is not much useful for forming well-aligned nano fibres over large areas because the edge of such a bobbin has to be relatively sharp. ${ }^{80}$ Yarns of aligned polyethylene oxide (PEO) fibres have been produced by introducing an electrostatic lens element to stabilize the liquid jet by Deitzel et al. ${ }^{81}$ Fong et al. ${ }^{82}$ Electro spun aligned yarns of nylon- 6 by rapidly oscillating a grounded frame within the jet. Dersch et al. ${ }^{83}$ Used a metal frame as collector to produce well oriented parallel arrays of polyamide nano fibres with an average diameter of $50 \mathrm{~nm}$. The orientation is attributed to the polymer jet jumping back and forth from one side of the frame to the other because of the electrostatic charging effects. Li et al. ${ }^{13}$ have collected the electrospun nano fibres over a gap formed between two conductive substrates for generating uniaxially aligned arrays of polymers, ceramics and composite materials. As a result of electrostatic interactions, the nano fibres were stretched to form a parallel array across the gap. Matthews et al. ${ }^{28}$ have used a rotating mandrel as the collector.

There are many other modifications of the collector for generating aligned electrospun fibres such as spinning onto the sharp edge of a thin rotating wheel. ${ }^{84}$ In order to reduce the effect of electrostatic field at the tip and to avoid corona discharge, Jaeger et al ${ }^{85}$ used twoelectrode setup by placing an additional ring electrode in front of the capillary. The additional electrode helps in establishing a stable field which then leads to avoid the shape change at the tip. The collection of nano fibres onto a water reservoir collector and drawing of the nonwoven web of fibres across the water has also been investigated. ${ }^{86}$ Dabirian et al. ${ }^{21}$ in order to produce uniaxially aligned PAN nano fibre yarn, employed a negative charged bar in the electric field of the conventional electro spinning system which lead to the formation of an electrostatic multipolar field. The twisted yarn was collected by a rotating take up unit. Figure 2 illustrates various geometries of the collector used to align the nano fibres during electro spinning.

Take up velocity: Matthews et al. ${ }^{28}$ have investigated that random matrix of collagen fibrils are formed at a mandrel speed of less than 500rpm where as the fibrils are regularly deposited along the axis of rotation when the rpm was increased to 4500 . The effect of velocity of the rotating mandrel on crystallinity, mechanical properties and alignment of electrospun polyethylene terephthalate (PET) fibres was investigated by Kim et al. ${ }^{87}$ They investigated that the amount of amorphous region increased with the rotational speed of the mandrel as higher speed leads to rapid solidification and deposition of the fibres. They also investigated there is more regular alignment of fibres at higher speeds.

Ambient parameters: The atmospheric conditions from the tip of the syringe to the collector such as temperature, relative humidity, vacuum conditions and surrounding gas influence the morphology of electrospun fibres. High temperature makes the electro spinning process quick and produces more uniform fibre. It was observed by Baumgarden ${ }^{88}$ that at a relative humidity of more than $60 \%$, the electrospun acrylic nano fibres do not dry properly and get entangled on collector surface. The pore characteristics of PS fibres at varied relative humidity have been studied by Megelski et al. ${ }^{47}$ and Casper et $a .^{89}$ It was observed by them that at lower humidity, smooth and poreless fibres were produced. The increase in humidity resulted in formation of circular pores in smaller quantities and a further increase resulted in non uniform pores. Kim et al. ${ }^{90}$ observed that when the relative humidity is increased, mean fibre diameter is also increased. Polyamide- 6 was electrospun at temperatures ranging from 25 to $60^{\circ} \mathrm{C}$ and it was found that at higher temperatures the fibre diameter decreased which was attributed to the decrease in viscosity of the solution at higher temperatures..$^{91}$

\section{Structure and properties of nanofibres}

\section{Structure of nano fibres}

Electrospun nano fibres are normally collected as randomly oriented nonwoven mat. These fibres have smaller pores and higher surface area than regular fibres. The pronounced nano and micro structural characteristics of nano fibres enable to develop advanced materials with sophisticated applications. Though the electrospun nano fibres are circular in cross section, other shapes such as rectangular cross section with ribbon like structure, ${ }^{92}$ hollow structure has also been produced. The structure of nano fibres can be analyzed by various techniques which are discussed below.

Characterization of nano fibres: The macroscopic morphology and surface texture are mainly investigated by Scanning Electron Microscopy (SEM), Transmission Electron Microscopy (TEM), Wide Angle X-Ray Diffraction (WAXD) and Small Angle X-Ray Scattering (SAXS). ${ }^{93}$ Many researchers have studied the morphology of various novel nano-surfaces by SEM. It is very simple and most widely used for morphological analysis. Though TEM is used by many researchers as an essential tool for qualitative analysis, structural defect analysis and spatial distribution study of nano fibres, it is time consuming and does not provide quantitative information. Mathias et al. ${ }^{94}$ quantitatively characterized the nanostructure and crystallite structure in nylon-6 based nanostructures. WAXD is also widely used to study the nano fibre structure by monitoring the position, shape and intensity of the basal reflections. WAXD doesn't provide much information regarding the spatial distribution or any structural defects in nano fibres.

Differential Scanning Calorimetry (DSC) and thermos-gravimetric analysis (TGA) are used to analyse the thermal behaviour. The local structure and chemical composition were interpreted by field emission SEM and energy dispersive spectroscopy respectively by Gupta and Wilkes. The molecular structure of nano fibre can be characterized by various techniques such as nuclear magnetic resonance (NMR), Fourier 
transform infrared (FTIR), small angle X-ray scattering (SAXS), W-ray diffraction and optical birefringence. X-ray photoelectron spectroscopy and water contact angle measurement techniques can be used for analysis of chemical properties. The porosity and pore parameters in the inter fibre region were determined by mercury intrusion technique using an Autopore III mercury porosimeter. The pore size distribution was measured by a capillary flow porometer and the pesticide repellency, retention and penetration were assessed according to ASTM F 2130-0124. ${ }^{95}$ Raman Spectroscopy, Fourier Transform Infrared Spectroscopy and wide angle X-ray diffraction (WAXD) were used for analyzing the secondary structure, chemical composition and crystallinity of the electrospun silk fibroin..$^{96}$

\section{Properties of nano fibres}

The surfaces generated by electro spinning have novel and high performance properties. Electrospun nano fibres possess noticeable differences in their thermal, mechanical and electrical properties as compared to normal fibres. This section highlights the properties of nano fibres.

Thermal properties: The thermal properties of nano fibres can be analyzed by differential scanning calorimetry (DSC). Zong et $a{ }^{68}$ observed that electrospun nano fibres of PLLA posses lower crystallinity, melting temperature $(\mathrm{Tm})$ and glass transition temperature $(\mathrm{Tg})$ than semi crystalline PLLA resins. The low crystallinity can be attributed to the high rate of evaporation and rapid solidification before their collection onto the collector. The decrease in $\mathrm{Tg}$ and $\mathrm{Tm}$ is due to the large surface area to volume ratio of nano fibres with air as plasticizer. The lower heat of fusion and melting temperature of PEO nano fibres as compared to the PEO powder was attributed to the decreased crystallinity after electro spinning. The thermal degradation and decrease in molecular weight of PET and polyethylene naphthalate (PEN) nano fibres were attributed to the decrease in the $\mathrm{Tg}$ and $\mathrm{Tm}$ after electro spinning.

Mechanical properties: The mechanical properties of nano fibres such as tensile strength, elongation and modulus are affected by the surface morphology, pore size and distribution. The tensile strength of PVA fibre aggregate (measured by Instron with an extension rate of $100 \mathrm{~mm} / \mathrm{min}$ ) was found to increase with the increasing weight percentage of glyoxal to PVA while the elongation decreased. Dabirian et al. ${ }^{22}$ produced yarns of different linear density, twist level and material by modifying the electro spinning equipment. They measured the mechanical properties of the yarn by Zwick 1446-60 and observed that the yarn treated with boiling water under tension showed higher strength and lower strain which is because of the increase in degree of crystallinity in the treated samples. Fornes et al. ${ }^{97}$ observed that the stiffness of nano composites increased substantially by addition of organoclay such as montmorillonite. They also found that with the increase in clay content the ductility of polyamides gradually decreases.

Electrical properties: The electrical properties of nano fibres prepared from polyaniline/PEO blends ${ }^{98}$ and partially graphitized carbon nano fibres of $\mathrm{PAN}^{99}$ have been studied. The electrospun nano fibres containing CNTs have superior electrical properties (high energy densities and low driving voltages). ${ }^{100}$ The nano composites of ether/clay (organically modified) exhibit ionic conductivity which is several orders of magnitude higher than that of the corresponding clay. The intercalating of electro active polymers into clay minerals can further improve the conductivity. ${ }^{101}$

\section{Applications of Nano fibres}

Electro spinning is a simple technique to produce ultrathin fibres from a gamut of polymeric materials. The simplicity of the process, versatility of the materials suitable for use in electro spinning along with the unique features of nano fibres enables them for numerous applications. The nano fibres with high surface area and numerous pores have enormous applications in tissue scaffolds, nano composites, protective clothing, filtration, electronics and protective clothing.

\section{Biomedical applications}

A wide range of polymers have been successfully electrospun as nonwoven mats and used in biomedical application. Yoshimoto et al. ${ }^{102}$ used the biodegradable polycaprolactone (PCL) in electro spinning and investigated its potential for bone tissue engineering. They found that the PCL scaffolds provide an environment that supports mineralized tissue formation and may be used for the treatment of bone defects. It has been reported that the electrospun silk fibroin nano fibres promoted cell adhesion and spreading of type I collagen, as they provide a high level of surface area for cells to attach due to their three-dimensional feature, wide range of pore size distribution and high surface area to volume ratio. The degummed silk fibroin nano fibre nonwovens were applied for wound dressing and found to be favorable for cell attachment, growth and proliferation. Also the biomedical applications such as wound dressing and scaffolds for tissue engineering, ${ }^{103,104}$ of nano fibres have been studied. Xie $\& \mathrm{Hsieh}^{105}$ prepared enzyme loaded fibres by the electro spinning of a solution containing enzyme and PEO/PVA and found that the reactivity of the enzyme was 6 times higher.

It is reported that the electrospun collagen fibrils closely mimic and sometimes may even fully reproduce the structural biological properties of the natural polymer and hence holds great promise for a variety of bioengineering applications. Gibson et al. ${ }^{106}$ Produced electrospun fibres containing $\mathrm{pH}$-adjusting compound for use in wound dressing or protection from contamination. Electrospun fibre mats were produced from PLA, polyethylene co-vinyl acetate (PEVA) and their blend $(50,50)$ and the potential of the mats were also explored as drug delivery vehicles using tetracycline hydrochloride as a model drug. ${ }^{107}$ Matthews et al. ${ }^{42}$ produced scaffolds composed of collagen nano fibres and found that the structural properties varied with the tissue of origin, the isotope and the concentration of the collagen solution. Huang et al. ${ }^{108}$ Produced collagen containing nano fibres and nonwoven fabrics that have potential application in wound healing, tissue engineering and as hemostatic agents. They also produced elastin-mimetic fibres from peptide polymer in order to mimic protein fibres that are found in arterial wall.

\section{Electronic applications}

The performance of carbon nano fibres produced by carbonization of electrospun PAN fibre as electrode has been investigated by Yang $\&$ Kim. ${ }^{109}$ They found that the performance of these capacitors can be improved by controlling the activation temperature, the pore density and the structure. Yang \& $\mathrm{Kim}^{110}$ also investigated the application of nonwoven mats as super capacitors. Choi et al. ${ }^{111}$ investigated that the porous surfaces produced by electro spinning are good matrices for holding polymer electrolytes and can be used in the fabrication of high performance lithium batteries. Highly conducting fibres with less than $100 \mathrm{~nm}$ diameter were electrospun from sulfuric acid-doped polyaniline and their blends in polymers such as polystyrene (PS) and polyethylene oxide (PEO). ${ }^{112}$ To enhance the conductivity these nanofibres were coated with conducting polypyrole and gold.

Kessick et al. ${ }^{113}$ Prepared helical coils composed of a polyaniline and PS by electro spinning. Electronic polymers have been electrospun in order to develop nano scale electronic machines. ${ }^{14,115}$ Nano fibres 
with special arrangements of polymer molecules which can themselves function as nano machines to translate and rotate polymer molecule have also been produced1. Conducting nano fibers with the potential for applications in micro and optoelectronics such as nano wires, LEDs, photocells etc have also been investigated. ${ }^{116}$ Ziegler et al. ${ }^{117}$ developed a hybrid solar cell using electrospun conductive polymers doped with photovoltaic dyes and nano crystalline semiconductor particles.

\section{Nanofibre sensors}

Fluorescence based sensors have been fabricated by electrospun nano fibres containing fluorescent indicator as the active component. ${ }^{118}$ The sensitivities of these sensors to metal ions $\left(\mathrm{Fe}^{3+}\right.$ or $\left.\mathrm{Hg}^{2+}\right)$ were two to three orders of magnitude greater than those based on continuous thin films. Aussawasathien et al. ${ }^{119}$ also observed the improvement in sensitivity of sensors for humidity sensing, hydrogen peroxide and glucose sensing. Liu et al. ${ }^{120}$ recently fabricated gas sensors based on individual polyaniline nano fibres and established that these sensors and their assemblies have a great potential for the sensing technology. It was observed that the CNT-based sensors demonstrated 35 times increase in the strain sensing ability (as measured by voltage across the sensor) for only $0.05 \mathrm{wt} \%$ of the nano tube. The electro spinning process was used to develop a high surface area chemo-sensor material of fluorescent conjugated polymer. ${ }^{121}$ Wang et al. ${ }^{122}$ have generated fluorescent polymer film sensors useful for the detection of explosives by electro spinning process. Pellejero et al. ${ }^{123}$ have developed a nano material based humidity sensor for environmental and industrial process monitoring.

\section{Filter applications}

The nano scale fibre diameter and high specific area to volume ratio of electrospun materials are favorable for filtering applications as the filtering efficiency is inversely proportional to the diameter. ${ }^{124}$ The electrospun nonwoven membranes are well known in the filtration/ separation industry for their high filtration efficiency for small particles. ${ }^{125}$ The suitability of polyamide- 66 nano fibre coating for filtering applications was evaluated by Heikkila et al. ${ }^{126}$ They found that even a lowest weight of nano fibre coating $\left(0.02 \mathrm{~g} / \mathrm{m}^{2}\right)$ improved the filter efficiency and a coating weight of $0.50 \mathrm{~g} / \mathrm{m}^{2}$ removed approximately $90 \%$ or more from all aerosol particles regardless of the substrate material. Also the use of nano fibre membranes for filter applications was investigated. ${ }^{127}$ The removal of particles and droplets smaller than $100 \mathrm{~nm}$ from liquid or gasses is being achieved by using the nanofibres. The electrospun nano fibres were incorporated with magnetic components and the separation efficiency of magnetic particles was found to be increased by the application of an external electric field 125 . Graham et al. ${ }^{128}$ studied the application of electrospun nano fibres in pulse-clean cartridges for dust collection and cabin air filtration of mining vehicles.

\section{Protective textile materials}

For protective clothing applications, the nano fibre webs could be directly applied to garment systems92. Zoned materials in protective garments can be formed by spraying the nanofibres directly into 3-dimensional forms and varying the thickness of the web at various locations. The direct application eliminates the costly garment manufacturing steps and solves the seam related problems which is a limiting factor in protective garment. The US Army Natick Soldier Center investigated the potential of nano fibre webs in protective clothing. It was found that nano fibre webs of nylon 6,6 , polybenzimidazole, polyacrylonitrile and polyurethane provided good aerosol particle protection, without any change in their moisture vapour transfer properties. ${ }^{129}$ Protective clothing materials for agricultural workers were developed by using the electrospun polypropylene webs and laminates produced via melt-electro spinning. ${ }^{130}$

Protective garments that reduce soldiers' risk from chemical exposure have been designed from electrospun nanofibres. ${ }^{131}$ The transport properties of elastomeric electrospun mats have been investigated and suggested for using in protective clothing. ${ }^{132}$ The layered composite material were incorporated with electrospun nanofibres and utilized as protective clothing. ${ }^{133}$ Gibson et al. ${ }^{134} \mathrm{Applied}$ nano fibres coatings directly to a polyurethane foam containing activated carbon and suggested that it can be applied as a component for military chemical protective clothing systems.

\section{Miscellaneous applications}

The novel surfaces produced by electro spinning have found many other applications such as catalysis. ${ }^{135,136}$ Gibson $^{137}$ has developed breathable fabrics to be used as clothing from electrospun nanofibres of PAN and PBI. Custom-fit seamless clothing was obtained by spraying the electrospun fibres directly onto a $3 \mathrm{D}$ screen form obtained by $3 \mathrm{D}$ body scanning. ${ }^{134}$ Drew et al. ${ }^{138}$ have successful engineered photo-responsive nano fibre membrane by electro spinning a photonic polymer system (PAN blended with light harvesting azoic dyeCongo red). Nano composites are the promising material produced by reinforcing elements such that at least one of the dimensions is in nano range. The nano composites posses superior properties such as increased strength and modulus, increased heat and UV resistance, decreased gas permeability and flammability. ${ }^{139,140}$ The interaction between the nanofibres and the matrix material is significantly increased because of the high surface to volume ratio which results better reinforcement than conventional fibres. The significant increase in the mechanical strength of a rubber film by reinforcing with electrospun nanofibres of polybenzimidazole (PBI) has been investigated. ${ }^{141}$ The addition of electrospun of nylon nanofibres to an epoxy resin significantly improved both the stiffness and mechanical strength of the nanocomposite.

The electrospun piezoelectric nanofibres were applied in components on the wings of remotely controlled aircrafts. ${ }^{142}$ The electrospun nanofibres are the attractive class of solid supports for enzymes and conventional catalyst. ${ }^{143}$ The catalytic activity of palladium (Pd)-incorporated nanofibres for selective hydrogenation of dehydrolinalool was found to be 4.5 times higher than the $\mathrm{Pd}$ catalyst supported on $\mathrm{Al}_{2} \mathrm{O}_{3}$ powders. ${ }^{130}$ It was observed that the intensity of light scattered from nanofibres was dependant on the polarization direction of light. This observation was the basis for the use of uniaxially aligned nanofibres as inexpensive optical polarizers. The application of electrospun nanofibres as templates for the generation of nano fluid channels ${ }^{144}$ and for fabrication of nano scale mechanical oscillators ${ }^{145}$ has also been investigated. Fang et al. ${ }^{146}$ Used membranes of electrospun poly-D, L-lactide-co-glycolide for anti-adhesion applications.

\section{Limitations and future scopes}

A lot of research has been done on the fundamental aspects of electro spinning. The major concern which is to be resolved is the commercialization of the process and enhancement of the productivity. To resolve these issues more research and theoretical modeling are required on the basics of electro spinning and on the instability of the 
jets which influence the fibre diameter. The nano fibre should have consistent diameter and it should be free from beads. The number of polymers successfully electrospun up to now is around fifty. There is a need to explore the scope of other polymers, their property characterization and applications. The various factors affecting the morphology and properties of nanofibres is also to be established.

The major issue that is yet to be resolved is the scaling-up of the process for commercialization. The productivity of electro spinning is very low $\left(10 \mu \mathrm{l} / \mathrm{min}-10 \mathrm{ml} / \mathrm{min}\right.$ for single jet ${ }^{147}$ and $22.5 \mathrm{ml} / \mathrm{min}$ for a nine needle multiple jet ${ }^{148}$ ) and it needs to be increased manifold for their commercialization. ${ }^{149}$ Academic and research communities should join hands in taking the lab-scale technology to the commercial level. The production of various types of novel surfaces (such as porous, hollow, core/sheath and with special features) and to find out their suitability in different applications is to be investigated. ${ }^{150}$ The production of well aligned arrays of nano fibres having a great potential in material science needs to be developed.

Recently, polymer layered silicate (PLS) nano composites consisting superior properties are the main area of research. In this area more research are required to study the structure-property relationship, theoretical modeling and commercialization of the process. ${ }^{151}$ Though numerous methods to measure the tensile behavior of single nano fibre strands exist, there is a need to standardize these methods for accuracy and reproducibility. ${ }^{152}$ The potential of biodegradable polymer-based nano composites which are the entirely new type of materials also need to be investigated. ${ }^{153}$ The conjugated organic polymers which are very useful in flexible electronics have limitations in their molecular weight and/or solubility foe successful electro spinning.

The potential threat of nano particles on health and environment needs to be investigated. ${ }^{154,155}$ The exceptional properties of carbon nano particles may cause health hazards ${ }^{156}$ and there may be potential toxicity of such materials. ${ }^{157}$ The combustibility of nano particles because of their increased surface area is also a great concern. ${ }^{158}$

\section{Conclusion}

Electro spinning can produce various novel surfaces with nanoscale fibre diameter and also it is very simple as compared to traditional fibre forming methods. Though electro spun nano fibres are still at the embryonic stage, it has an emerging future in various applications. It is going to bring about hundreds of billions of dollars of market impact on new materials within a decade. Research and development will slowly break down the barriers for use of nano fibres in various fields. Also the advent of electro spinning makes it possible to bring the traditional textile sector to a level of high-technological industry. However, there is a need of intense cooperation between people from various disciplines such as textile technology, chemical technology, biotechnology, polymer science and material science to explore these possibilities.

\section{Acknowledgements}

None.

\section{Conflict of interest}

There is no conflict of interest.

\section{References}

1. Renker DH, Chun I. Nano metre diameter fibres of polymer, produced by electro spinning. Nanotechnology. 1996;7:216-223.
2. Ziabicki A. Fundamentals of fibre formation: the science of fibre spinning and drawing. New York: Wiley; 1976.

3. Nayak R, Padhye R, Lyndon A. Recent advancements in electro spinning process. Melliand International. 2010;9(3):17-18.

4. Bhattarai SR, Bhattarai N, Yi HK, et al. Biomaterials. 2004;25:2595.

5. Nayak R, Kyratzis IL, Truong YB, et al. Fabrication and characterization of nanofibres by melt blowing and melt electro spinning. Advanced Materials Research. 2012;472:1294-1299.

6. Bergshoef MM, Vancso G. Transparent Nano composites with U1trathin, Electrospun Nylon-4,6 Fiber Reinforcement. J Adv Mater. 1999;11(16):1362-1365.

7. Hajra MG, Mehta K, Chase GG. Sep Purif Technol. 2003;30:79.

8. Larmor J. Royal Society. 1898;63:365.

9. Shin YM, Hohman MM, Brenner MP, et al. Electro spinning: A whipping fluid jet generates submicron polymer fibers. Appl Phys Lett. 2001;78(8):1149.

10. Li D, Xia Y. Electro spinning of Nano fibers: Reinventing the Wheel? $J$ Adv Mater. 2004;16(14):1151-1170.

11. Nayak R, Kyratziset IL, Truong YB, et al. Melt-electrospinning of polypropylene with conductive additives. $J$ Material Science. 2012;47(17):6387-6396.

12. Li D, Wang Y, Xia Y. Electro spinning of Polymeric and Ceramic Nano fibers as Uniaxially Aligned Arrays. Nano Lett. 2003;3(8):1167-1171.

13. Larrondo L, Manley J. Electrostatic fiber spinning from polymer melts. I. Experimental observations on fiber formation and properties. $J$ Polym Sc. 1981;19(6):909-920.

14. Vaia RA, Vasudevan S, Krawiec W, et al. New polymer electrolyte nano composites: Melt intercalation of poly (ethylene oxide) in mica-type silicates. Adv Mater. 1995;7(2):154-156.

15. Doshi J, Renker DH. J Electrostat. 1995;35: 151.

16. Nayak R, Kyratziset IL, Truong YB, et al. Structural and mechanical properties of polypropylene nanofibres fabricated by melt blowing. $J$ Textile Institute. 2014;106(6):629-640.

17. Kim JS, Lee DS. Thermal Properties of Electrospun Polyesters. Polymer J. 2000;32:616-618.

18. Kim JS, Renker DH. Polybenzimidazole nano fiber produced by electro spinning. Polym Engng Sc. 1999;39(5):849-854.

19. Fong H, Renker DH. Elastomeric nano fibers of styrene-butadiene-styrene tri block copolymer. J Polym Sc. 1999;37(24):3488-3493.

20. Nayak R. Fabrication of submicron fibres by melt blowing and melt electro spinning. In ICNFA 2011: 2nd International Conference on Nanotechnology: Fundamentals and Applications, ASET Inc, Canada; 2011.

21. Bognitzki M, Czado W, Frese T, et al. Nano structured Fibers via Electro spinning. Adv Mater. 2001;13(1):70-72.

22. Bognitzki M, Frese T, Steinhart M, et al. Preparation of fibers with nano scaled morphologies: Electro spinning of polymer blends. Polym Engng Sc. 2001;41(6):982-989.

23. Jeager R, Berghoef MM, Batlle CM, et al. Electro spinning of ultra-thin polymer fibers. Macrmol Symp. 1998;127(1):141-150.

24. Dabirian F, Hosseini Y, Ravandi SAH. Manipulation of the electric field of electro spinning system to produce polyacrylonitrile nano fiber yarn. J Text Inst. 2007;98(3):237-241.

25. Lee S, Obendorf SK. Barrier effectiveness and thermal comfort of protective clothing materials. Text Res J. 2007;98(2):87-98. 
26. Krishnappa RVN, Sung C, Heidi S-G. Electro spinning of Polycarbonates and their Surface Characterization using the SEM and TEM. Mat Res Soc Symp Proc. 2002;702:235.

27. Wu Y, Yu JY, Chi Ma. Electrospun Nano porous Fiber. Text Res J. 2008;78(9):812-815.

28. Ding B, Kim HY, Lee SC, et al. Preparation and characterization of nano scale poly (vinyl alcohol) fiber aggregate produced by an electro spinning method. J Polym Sc-B-Polym Phy. 2002;40(13):1261-1268.

29. Nayak R. Production of novel surfaces by electro spinning. Acta Universitatis Cibiniensi. 2011;58:128-138.

30. Sun Z, Zussman E, Yarin AL, et al. Compound Core-Shell Polymer Nano fibers by Co-Electro spinning. Adv Mater. 2003;15(22):1929-1932.

31. Pinto NJ, Zhou YX, Freitag M, et al. Book of Abstracts-Fibre Society, Fall Technical Meeting. 2003.

32. Kit K, Jagannathan S. Book of Abstracts-Fibre Society, Fall Technical Meeting. 2002.

33. Zacharides AE, Porter RS, Doshi J, et al. Polym News. 1995;20:206

34. Gupta P, Wilkes GL. Polymer. 2003;44:6353.

35. Ma M, Mao Y, Gupta M, et al. Super hydrophobic Fabrics Produced by Electro spinning and Chemical Vapor Deposition. Macromolecules. 2005;38(23):9742-9748.

36. Li D, Babel A, Jenekhe SA, et al. Nano fibers of Conjugated Polymers Prepared by Electro spinning with a Two-Capillary Spinneret. $A d v M a$ ter. 2004;16(22):2062-2066

37. Madhugiri S, Dalton A, Gutierrez J, et al. Electrospun MEH-PPV/SBA15 Composite Nano fibers Using a Dual Syringe Method. J Am Chem Soc. 2003;125(47):14531-14538.

38. Fang X, Renker DH. DNA fibers by electro spinning. J Macromol Sc-Phy. 1997;36(2):169-173.

39. Santin M, Motta A, Freddi G, et al. In vitro evaluation of the inflammatory potential of the silk fibroin. J Biomed Mater Res. 1999;46(3):382-389.

40. Park WH, Ha WS, Ito $\mathrm{H}$, et al. Relationships between anti thrombogenicity and surface free energy of regenerated silk fibroin films. Fibres Polym. 2001;2(2):58-63.

41. Buckho JC, Chen LC, Shen Y, et al. Polym. 1999;40:7397.

42. Min BM, Lee G, Kim SH, et al. Biomaterials. 2004;25:1289.

43. Jin HJ, Fridrikh SV, Rutledge GC, et al. Electro spinning Bombyx mori Silk with Poly (ethylene oxide). Bio macromolecules. 2002;3(6):1233-1239.

44. Matthews JA, Wnek GE, Simpson DG, et al. Electro spinning of Collagen Nano fibers. Bio macromolecules. 2002;3(2):232-238.

45. Lou CW, Lin JH, Yen KC, et al. Preparation of Polyethylene Oxide/ Chitosan Fiber Membranes by Electro spinning and the Evaluation of Biocompatibility. Text Res J. 2008;78(3):254-257.

46. Nayak R, Kyratziset IL, Truong YB, et al. Effect of viscosity and electrical conductivity on the morphology and fibre diameter in melt electro spinning of polypropylene. Textile Research J. 2013;83(6):606-617.

47. Kataphinan W, Dabney S, Reneker DH, et al. Patent WO0126610, University of Akron, USA; 2001.

48. Boland ED, Matthews JA, Pawlowski KJ, et al. Electro spinning Collagen And Elastin: Preliminary Vascular Tissue Engineering. Frontiers in Bioscience. 2004;9(2):1422-1432.

49. Li D, Xia Y. Fabrication of Titania Nano fibers by Electro spinning. Nano Lett. 2003;3(4):555-560.
50. Yoshida M, Prasad PN. Sol-Gel-Processed $\mathrm{SiO}_{2} / \mathrm{TiO}_{2} / \mathrm{Poly}$ (vinylpyrrolidone) Composite Materials for Optical Waveguides. Chem Mater. 1996;8(1):235-241.

51. Kataphinan W, Mensah RT, Evans EA, et al. High-temperature fiber matrices: Electro spinning and rare-earth modification. J Vac Sc Tech A: Vac Surf Films. 2003;21:1574.

52. Li D, Herricks T, Xia Y. Magnetic nano fibers of nickel ferrite prepared by electro spinning. Appl Phys Lett. 2003;83(22):4586.

53. Dai H, Gong J, Kim H, et al. Nanotechnology. 2002;13:674.

54. Bowling GL, Matthews JA, Simpson DG, et al. J Text Apparel Technol Manag, The Fiber Society Spring 2001 Conference. Raleigh NC, USA; 2001 .

55. Sen R, Zhao B, Perea D, et al. Preparation of Single-Walled Carbon Nano tube Reinforced Polystyrene and Polyurethane Nano fibers and Membranes by Electro spinning. Nano letters. 2004;4(3):459-464.

56. Ko FK, Khan S, Ali A, et al. Structure and properties of carbon nano tube reinforced nano composites, collection of technical papers-AIAA ASME/ ASCE/ AHS/ ASC Structures. Structural Dynamics and Materials Conference. 2002;3:1779.

57. Park C, Ounaies Z, Watson KA, et al. Polymer-single wall carbon nano tube composites for potential spacecraft applications. Materials Research Society Symposium Proceedings. 2001.

58. Laxminarayana K, Jalili N. Functional Nano tube-based Textiles: Pathway to Next Generation Fabrics with Enhanced Sensing Capabilities. Text Res J. 2005;75(9):670-680.

59. Demir MM, Yilgor I, Yilgor E, et al. Polymer 2002;43:3303

60. Fong H, Chun I, Reneker DH. Polymer. 1999;40:4585.

61. Kenawy ER, Layman JM, Watkins JR, et al. Biomaterials. 2003;24:907.

62. Fridrikh SV, Yu JH, Brenner MP, et al. Controlling the fiber diameter during electro spinning. Physical Rev Lett. 2003;90(14):144502.

63. Bognitzki M, Wendorff JH, Greiner A. Polym Prep. 2000;82:115.

64. Li D, Xia Y. Fabrication of Titania Nano fibers by Electro spinning. Nano Lett. 2003;3(4):555-560.

65. Theron SA, Zussman E, Yarin AL. Polymer. 2004;45: 2017

66. Zong XH, Kim K, Fang DF, et al. Polymer. 2002;43:4403.

67. Shin YM, Hohman MM, Brenner MP, et al. Polymer. 2001;42:9955.

68. Koski A, Yim K, Shivkumar S. Mater Lett. 2004;58:493.

69. Gupta P, Elkins C, Long TE, et al. Polymer. 2005;46:4799.

70. Lee KH, Kim HY, La YM, et al. Influence of a mixing solvent with tetrahydrofuran and N,N-dimethylformamide on electrospun poly(vinyl chloride) nonwoven mats. $J$ Polym Sc (Part B) Polymer Physics. 2002;40(19):2259-2268.

71. Bognitzki M, Czado W, Frese T, et al. Nano structured Fibers via Electro spinning. Adv Mater. 2001;13(1):70-72.

72. Ding B, Kimura E, Sato T, et al. Polymer. 2004;45:1895.

73. Li D, Babel A, Jenekhe SA, et al. Nano fibers of Conjugated Polymers Prepared by Electro spinning with a Two-Capillary Spinneret. Adv Mater. 2004;16(22):2062-2066.

74. Kilic A, Oruc F, Demir A. Effects of Polarity on Electro spinning Process. Text Res J. 2008;78(6):532-539.

75. Kessick R, Fenn J, Tepper G. Polymer. 2004;4:2981.

76. Kidoaki S, Kwon K, Matsuda T. Biomaterials. 2005;26:37. 
77. Megelski S, Stephens JS, Chase DB, et al. Micro- and Nano structured Surface Morphology on Electrospun Polymer Fibers. Macromolecules. 2002;35(22):8456-8466.

78. Sundaray B, Subramanian V, Natarajan TS. Electro spinning of continuous aligned polymer fibers. Appl Phys Lett. 2004;84(7):1222.

79. Katta P, Alessandro M, Ramsier RD, et al. Continuous Electro spinning of Aligned Polymer Nano fibers onto a Wire Drum Collector. Nano Lett. 2004;4(11):2215-2218.

80. Theron A, Zussman E, Yarin AL. Nanotechnology. 2001;12:384.

81. Deitzel JM, Kleinmeyer JD, Hirvonen JK, et al. Polymer. 2001;42:8163.

82. Fong H, Liu WD, Wang CS, et al. Polymer. 2002;43:775.

83. Dersch R, Liu T, Schaper AK, et al. Electrospun nano fibers: Interna structure and intrinsic orientation. J Polymer Sc. 2003;41(4):545-553.

84. Zussmann E, Theron A, Yarin AL. Formation of nano fiber crossbars in electro spinning. J Appl Phys Lett. 2003;82(6):973.

85. Jaeger R, Bergshoef MM, Batlle CMI, et al. Electro spinning of ultra-thin polymer fibers. Macromol Symp. 1998;127(1):141-150.

86. Smit E, Buttner U, Sanderson RD. Polymer. 2005;46:2419

87. Kim KW, Lee KH, Khil MS, et al. The effect of molecular weight and the linear velocity of drum surface on the properties of electrospun poly (ethylene terephthalate) nonwovens. Fibre Polym. 2004;5(2):122-127.

88. Baumgarten PK. J Colloid Interface Sc. 1971;36:71.

89. Casper CL, Stephens JS, Tassi NG, et al. Controlling Surface Morphology of Electrospun Polystyrene Fibers: Effect of Humidity and Molecular Weight in the Electro spinning Process. Macromolecules. 2004;37(2):573-578.

90. Kim GT, Lee JS, Shin JH, et al. Microscop Microanalysis Microstruc. 2004;10:554.

91. Mit-Uppatham C, Nithitanakul M, Supaphol P. Ultrafine Electrospun Polyamide-6 Fibers: Effect of Solution Conditions on Morphology and Average Fiber Diameter. Macromol Chem Phys. 2004;205(17):2327-2338

92. Krishnappa RVN, Desai K, Sung C. Morphological study of electrospun polycarbonates as a function of the solvent and processing voltage. $J$ Mater Sc. 2003;38(11):2357-2365.

93. Patanaik A, Anandjiwala RD, Rengasamy RS, et al. Text Progress. 2007;39:267.

94. Mathias LJ, Davis RD, Jarrett WL. Observation of $\alpha$ and $\gamma$ Crystal Forms and Amorphous Regions of Nylon 6-Clay Nano composites Using Solid-State 15N Nuclear Magnetic Resonance. Macromolecules. 1999;32(23):7958-7960.

95. Li WJ, Laurencin CT, Caterson EJ, et al. Electrospun nano fibrous structure: A novel scaffold for tissue engineering. J Biomed Mater Res. 2002;60(4):613-621.

96. Ayutsedea J, Gandhib M, Sukigarac S, et al. Polymer. 2005;46:1625.

97. Fornes TD, Yoon PJ, Keskkula H, et al. Polymer. 2001;42:9929.

98. Zhou Y, Freitag M, Hone J, et al. Fabrication and electrical characterization of polyaniline-based nano fibers with diameter below $30 \mathrm{~nm}$. Appl Phys Lett. 2003;83(18):3800.

99. Wang Y, Santigano-Aviles JJ. Large negative magneto resistance and two-dimensional weak localization in carbon nano fiber fabricated using electro spinning. J Appl Phys. 2003;94(3):1721.

100. Baughman RH, Cui C, Zakhidov AA, et al. Carbon nano tube actuators. Science. 1999;284(5418):1340-1344.
101. Hitzky ER, Aranda P, Casal B, et al. Nano composite materials with controlled ion mobility. Adv Mater. 1995;7(2):180-184.

102. Yoshimoto H, Shin YM, Terai H, et al. A biodegradable nano fiber scaffold by electro spinning and its potential for bone tissue engineering. Biomaterials. 2003;24(12):2077-2082.

103. Boland ED, Bowlin GL, Simpson DG, et al. Electro spinning of tissue engineering scaffolds. Polym Mater. 85:51-52.

104. Ma H, Zeng J, Realff ML, et al. Processing, structure, and properties of fibers from polyester/carbon nano fiber composites. Composites $S c \&$ Technol. 2003;63:1617.

105. Xie J, Hsieh YL. Ultra-high surface fibrous membranes from electro spinning of natural proteins: casein and lipase enzyme. J Mater Sc. 2003;38(10):2125-2133.

106. Gibson P, McManus A, Mello C. Patent WO0127365, University of Akron, USA; 2001.

107. Kenawy ER, Bowlin GL, Mansfield KJ. Release of tetracycline hydrochloride from electrospun poly (ethylene-co-vinylacetate), poly(lactic acid), and a blend. J Control Release. 2002;81(1-2):57-64.

108. Huang L, McMillan RA, Apkarian RP, et al. Generation of Synthetic Elastin-Mimetic Small Diameter Fibers and Fiber Networks. Macromolecules. 33(8): 2989-2997.

109. Kim C, Yang KS. Appl Phys Lett. 2003;94:1721.

110. Kim C, Yang KS. Appl Phys Lett. 2003;94:1216.

111. Choi SW, Jo SM, Lee WS, et al. An Electrospun Poly(vinylidene fluoride) Nanofibrous Membrane and Its Battery Applications. Adv Mater. 2003;15(23):2027-2032.

112. MacDiarmid AG, Jones WE, Norris ID, et al. 2001;119(1-3):27-30.

113. Kessick R, Tepper G. Microscale polymeric helical structures produced by electrospinning. Appl Phys Lett. 2004;84(23):4807.

114. Diaz de Leon MJ. Electrospinning nanofibres of polyaniline and polyaniliney (polystyrene and polyethylene oxide) blends. National Conference of Undergraduate Research. University of Kentucky, USA; 2001. p. 1-5.

115. MacDiarmid AG, Jones WE, Noris ID. Synthetic Metals. 2001;119:27.

116. Norris ID, Shaker MM, Ko FK, et al. Synthetic Metals. 2000;118:109.

117. Ziegler D, Senecal KJ, Dew C, et al. Electrospun fibrous membranes of photovoltaic and conductive polymers, J Text Apparel Technol Manage, The Fiber Society, Spring 2001 Conference. Raleigh, USA; 2001.

118. Wang X, Drew C, Lee SH, et al. Electrospun Nano fibrous Membranes for Highly Sensitive Optical Sensors. Nano Lett 2002;2(11):1273-1275.

119. Aussawasathien D, Dong J-H, Dai L. Synthetic Metals. 2005;154:37.

120. Liu H, Kameoka J, Czaplewski DA, et al. Polymeric Nano wire Chemical Sensor. Nano Lett. 2004;4(4):671-675.

121. Zhang Y, Dong H, Norris ID, et al. Abstracts of papers of the American Chemical Society. 2001.

122. Wang XY, Lee SH, Drew C, et al. Fluorescent electrospun polymer films for the detection of explosives, Abstracts of papers of the American Chemical Society. 2002.

123. Pellejero I, Urbizterido M, Izquierdo D, et al. An Optochemical Humidity Sensor Based on Immobilized Nile Red in Y Zeolite. Industrial \& Engg Chemistry Res. 2007;46(8):2335-2341.

124. Hinds WC. Aerosol Technology: Properties, Behaviour and Measurement of Airborne Particles. 2nd edn. John Wiley and Sons, New York, USA;1982. p. 504.

125. http://www.donaldson.com/ 
126. Heikkila P, Sipila A, Peltola M, et al. Electrospun PA-66 Coating on Textile Surfaces. Text Res J. 2007;77(11):864-870.

127. Gibson P, Schreuder GH, Rivin D. Colloids Surf A Physicochem Engg Asp 2001;187:469.

128. Graham K, Ouyang M, Raether MT, et al. Polymeric nano fibers for air filtration applications. 15th Annual Technical Conference and Expo of the American Filtration and Separations Society, Galveston, USA; 2002. p. $9-12$.

129. Gibson HS, Gibson P, Senecal K, et al. J Adv Mater. 2002;34:44.

130. Lee S, Obendorf SK. Developing protective textile materials as barriers to liquid penetration using melt-electro spinning. J Appl Polym Sc. 2006;102(4):3430-3437.

131. Ross SE. Int Fibre J. 2001

132. Gibson PW, Gibson HLS, Riven D, AIChE J. 1999;45:190.

133. Graham K, Gogins M, Gibson HS. Cooperative Charging Effects of Fibers from Electros pinning of Electrically Dissimilar Polymers. Int Nonwoven J 2004;13:21.

134. Gibson P, Gibson HS, Pentheny C. J Coated Fabrics. 1998;28:63.

135. Cheryl LC, Stephens JS, Tassi NG, et al.Controlling Surface Morphology of Electrospun Polystyrene Fibers: Effect of Humidity and Molecular Weight in the Electro spinning Process. Macromolecules. 2004;37(2):573-578.

136. Xie J, Hsieh Y-L. et al. Ultra-high surface fibrous membranes from electro spinning of natural proteins: casein and lipase enzyme. J Mater Sc. 2003;38(10):2125-2133.

137. Gibson HS. Electro spinning technology: a novel way to apply polymers directly to a substrate. The Eighth International Conference on Textile Coating \& Laminating, Frankfurt, Germany; 1998.

138. Drew C, Wang X, Senecal K. Electrospun nano fibers of electronic and photonic polymer systems, Orlando, TANDEC, Florida, USA; 2000.

139. Bharadwaj RK. Modeling the Barrier Properties of Polymer-Layered Silicate Nano composites. Macromolecules. 2001;34(26):9189-9192.

140. Giannelis EP. Polymer Layered Silicate Nano composites. Adv Mater. 1996;8(1):29-35.

141. Kim JS, Reneker DH. Mechanical properties of composites using ultrafine electrospun fibers. Polym Compos. 1999;20(1):124-131.
142. http://techreports.larc.nasa.gov/1trs/PDF/2003aiaa/NASA-aiaa-2003-1768.pdf

143. Jia H, Zhu G, Vugrinovich B, et al. Enzyme-Carrying Polymeric Nano fibers Prepared via Electro spinning for Use as Unique Biocatalysts. Biotechnol Prog. 2002;18(5):1027-1032.

144. Czaplewski DA, Kameoka J, Mathers R, et al. Nano fluidic channels with elliptical cross sections formed using a non lithographic process. Appl Phys Lett. 2003;83:4836.

145. Czaplewski DA, Verbridge SS, Kameoka J, et al. Nano mechanical Oscillators Fabricated Using Polymeric Nano fiber Templates. Nano Lett. 2004;4(3):437-439.

146. Fang D, Zong X, Chen W, et al. J Text Apparel Technol Manag, The Fiber Society Spring Conference, Raleigh NC, USA; 2001.

147. Huang Z-M, Zhang Y-Z, Kotaki M, et al. A review on polymer nano fibers by electro-spinning applications in nano composites. Comp Sc Tech. 2003;63:2223-2253.

148. Theron SA, Yarin AL, Zussman E, et al. Polymer. 2005;46:2889.

149. Yarin AL, Zussman E. Polymer 2004;45: 2977.

150. Teo WE, Ramakrishna S. A review on electro spinning design and nano fibre assemblies. Nanotechnology. 2008;17(14):R89-R106.

151. Zeng $\mathrm{QH}, \mathrm{Yu} \mathrm{AB}, \mathrm{Lu} \mathrm{GQ}$, et al. Clay-based polymer nano composites: research and commercial development. J Nanosc Nanotech 2015;5(10):1574-1592.

152. Inai R, Kotaki M, Ramakrishna S. Structure and properties of electrospun PLLA single nanofibres. Nanotechnology. 2005;16(2):208-213.

153. Hussain F, Hojjati M, Okamoto M, et al. eview article: Polymer-matrix Nano composites, Processing, Manufacturing, and Application: An Overview. J Comp Maters. 2006;40(17):1511-1575.

154. Nayak R, Kyratziset IL, Truong YB, et al. Recent advances in nano fibre fabrication techniques. Textile Research J 2012;82(2):129-147.

155. Warheit DB. Carbon 2006;44:1064

156. Borm PJ. Particle toxicology: from coal mining to nano technology. Inhal Toxicol. 2002;14(3):311-324.

157. Toensmeier PA. Plastics Engg. 2004;60:14.

158. Nano science and Nanotechnologies. The Royal Society and The Royal Academy of Engineering. London, UK; 2004. 